\title{
Management of Hematometra in Single Horn of Didelphic Uterus with Obstructed Hemivagina and Ipsilateral Renal Agenesis Syndrome: A Case Report with Brief Review of Literature
}

\author{
${ }^{1}$ Vineet V Mishra, ${ }^{2}$ Ritu Agarwal, ${ }^{3}$ Pradeep Bandwal, ${ }^{4}$ Sumesh Choudhary, ${ }^{5}$ Khushali Gandhi
}

\begin{abstract}
The triad of uterus didelphys with obstructed hemivagina and ipsilateral renal agenesis (OHVIRA) syndrome is a rare entity. These cases are difficult to diagnose due to heterogeneous presentation and rarity of the condition. Ultrasonography and magnetic resonance imaging are important for initial diagnosis; however, laparoscopy is required for the confirmation of the diagnosis. Early and accurate diagnosis of this condition followed by prompt surgical therapy is essential to prevent complications and to preserve future fertility. Here we report a case of uterus didelphys with hemivagina and ipsilateral renal agenesis with hematometra and hematosalpinx in a young girl.
\end{abstract}

Keywords: Didelphic uterus, Hematometra, Hematosalpinx, Hemivagina, Renal agenesis.

How to cite this article: Mishra VV, Agarwal R, Bandwal P, Choudhary S, Gandhi K. Management of Hematometra in Single Horn of Didelphic Uterus with Obstructed Hemivagina and Ipsilateral Renal Agenesis Syndrome: A Case Report with Brief Review of Literature. J South Asian Feder Obst Gynae 2016;8(3):231-235.

Source of support: Nil

Conflict of interest: None

Date of received: 8 May 2016

Date of acceptance: 12 June 2016

Date of publication: July 2016

\section{INTRODUCTION}

Mullerian duct anomalies (MDA) are developmental defects involving female reproductive system with presentations varying from undiagnosed very mild segmental abnormalities to unicornuate, bicornuate, didelphic uterus, and to even absence of uterus and vagina. Incidence of MDA is 0.5 to $5 \%$, while of didelphic uterus is 1 in $300,000 .{ }^{1,2}$ Mullerian anomalies with renal agenesis occur as a result of simultaneous arrest of development of

${ }^{1}$ Professor and Head, ${ }^{2,3}$ Senior Resident, ${ }^{4,5}$ Assistant Professor

${ }^{1-5}$ Department of Obstetrics and Gynecology, Institute of Kidney Diseases and Research Centre, Ahmedabad, Gujarat, India

Corresponding Author: Vineet $\mathrm{V}$ Mishra, Professor and Head Department of Obstetrics and Gynecology, Institute of Kidney Diseases and Research Centre, Ahmedabad, Gujarat, India e-mail: vineet.mishra.ikdrc@gmail.com mullerian and metanephric ducts at 8 weeks of gestational age. ${ }^{3}$ Didelphic uterus with obstructed hemivagina and ipsilateral renal agenesis (OHVIRA) syndrome is quite a rare anomaly. Incidence of this rare anomaly is not well known but it ranges between 0.1 and $3.8 \% .{ }^{4}$ Such patients usually present with pelvic pain at menarche, while others present with features of abscess formation like pain, fever, tenderness. A high index of suspicion is required for timely diagnoses and management of this rare condition so as to prevent its further complications. ${ }^{5}$ Here, we present a rare case of uterine didelphys with hemivagina with ipsilateral renal agenesis in a 13-year-old girl who presented with left hematometra and hematosalpinx.

\section{CASE REPORT}

A 13-year-old girl presented to outpatient department with lower abdominal pain for 10 days. She attained her menarche 6 months back with regular cyclical normal flow. She had a history of being operated for imperforate anus at two days of life. There was no other significant medical or surgical history. On examination, she was lean, thin-built with weight $35 \mathrm{~kg}$ and height of $145 \mathrm{~cm}$ (body mass index: $16.66 \mathrm{~kg} / \mathrm{m}^{2}$ ). Bilateral breasts were tanner stage 2 and axillary and pubic hairs were sparse. Her hemoglobin was $11.2 \mathrm{~g} \%$, total lymphocyte count was $8900 / \mathrm{mm}^{3}$, and platelets $4.3 \mathrm{lakh} / \mathrm{mm}^{3}$. Transabdominal ultrasonography revealed bicornuate bicollis uterus with left-side hematometra and hematosalpinx and normal right uterine cavity, as shown in Figures 1 and 2. Bilateral ovaries were normal. Right kidney was enlarged and malrotated while left kidney was absent. For pelvic anatomical details, magnetic resonance imaging (MRI) was advised, which revealed uterine didelphys with complete vertical septate vagina and left transverse vaginal septum. There was left-sided hematometra with hematosalpinx, while on right side the uterus, cervix, and vagina were normal, as shown in Figure 3. To complete her investigation workup, micturating cystogram was done which revealed bladder capacity to be $200 \mathrm{~mL}$ with grade 3 vesicoureteric reflux on right side with malrotated kidney, as shown in Figure 4. She was examined under anesthesia. The urethral meatus was lying on anterior vaginal wall somewhat distal to 
normal location. The patient was catheterized. Vulvovaginal examination revealed normal uterus with $5 \times 5 \mathrm{~cm}$ cystic to firm mass in left fornix, complete vertical vaginal septum, and a transverse vaginal septum on left side. Vaginoscopy

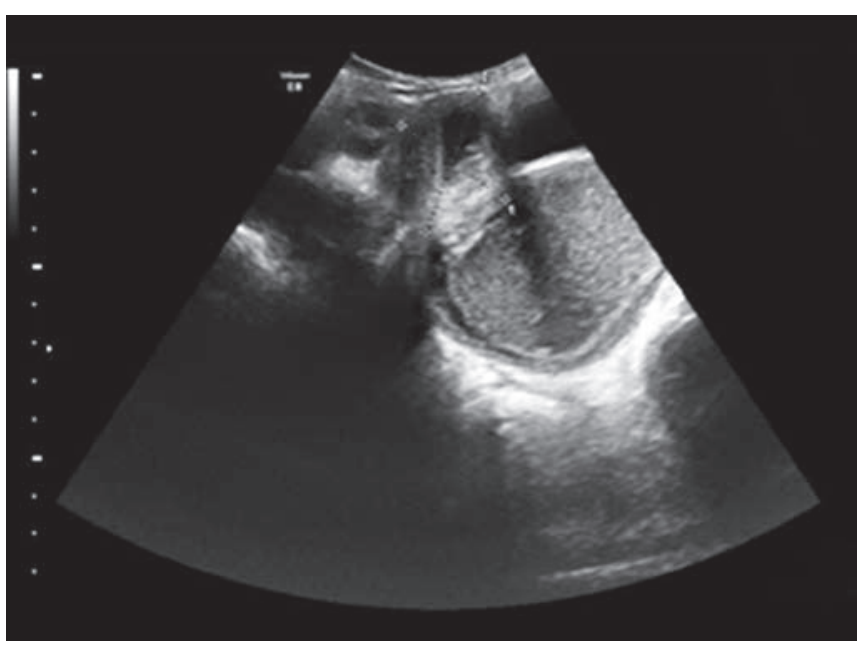

Fig. 1: Ultrasonographyic image showing left sided hematometra and hematocolpos

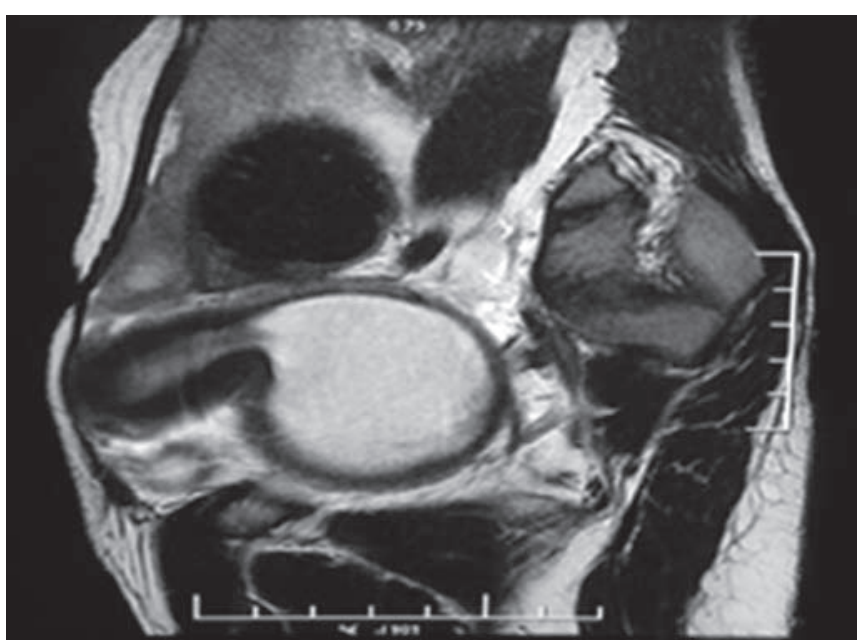

Fig. 3: Magnetic resonance image of left hematometra and hematocolpos

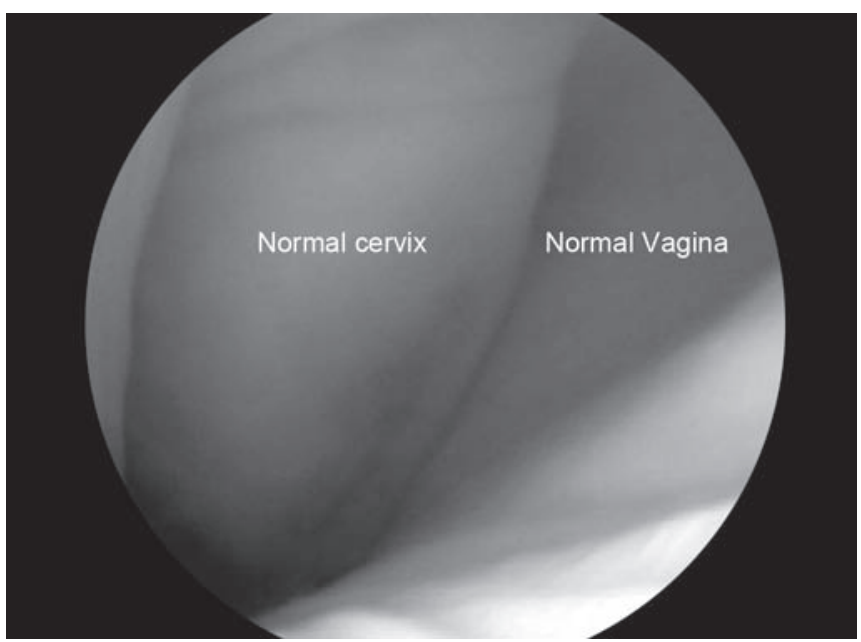

Fig. 5: Vaginoscopy revealing normal right cervix and vagina with hysteroscopy showed vagina, right cervix, right uterine cavity normal with right normal cornual opening as shown in Figures 5 and 6. Laparoscopy confirmed the findings of left hematometra with hematosalpinx

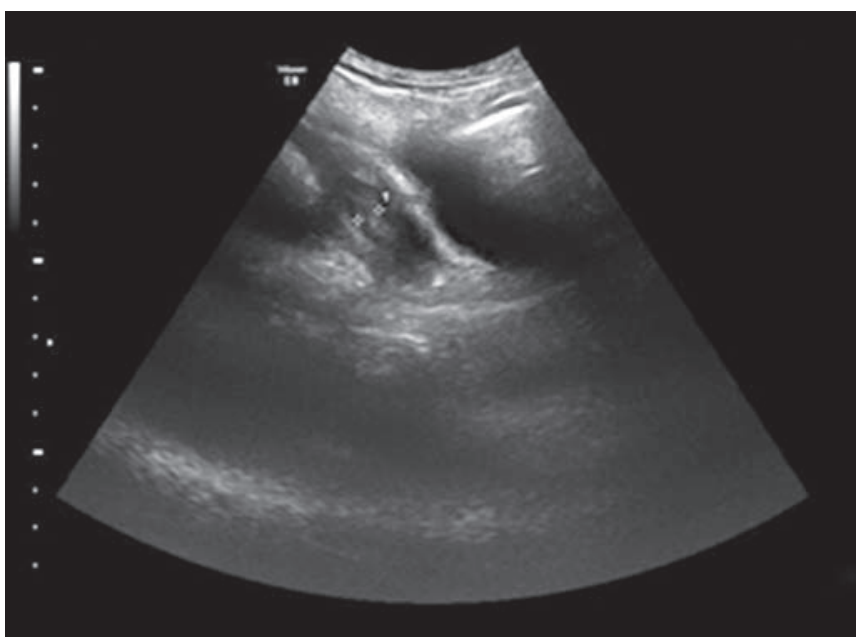

Fig. 2: Ultrasonography image showing normal right-sided uterine cavity
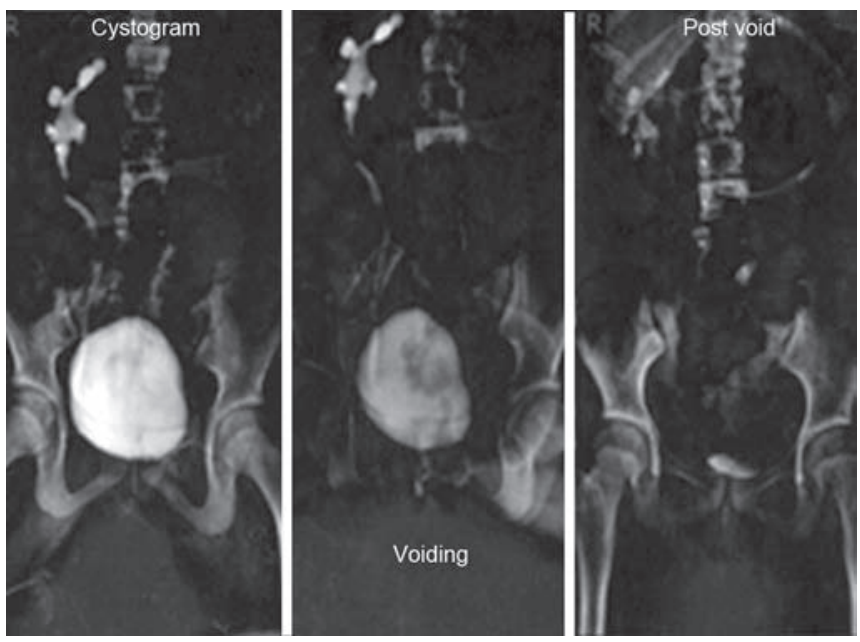

Fig. 4: Micturating cystourethrogram image showing malrotated right kidney with vesicoureteric reflux

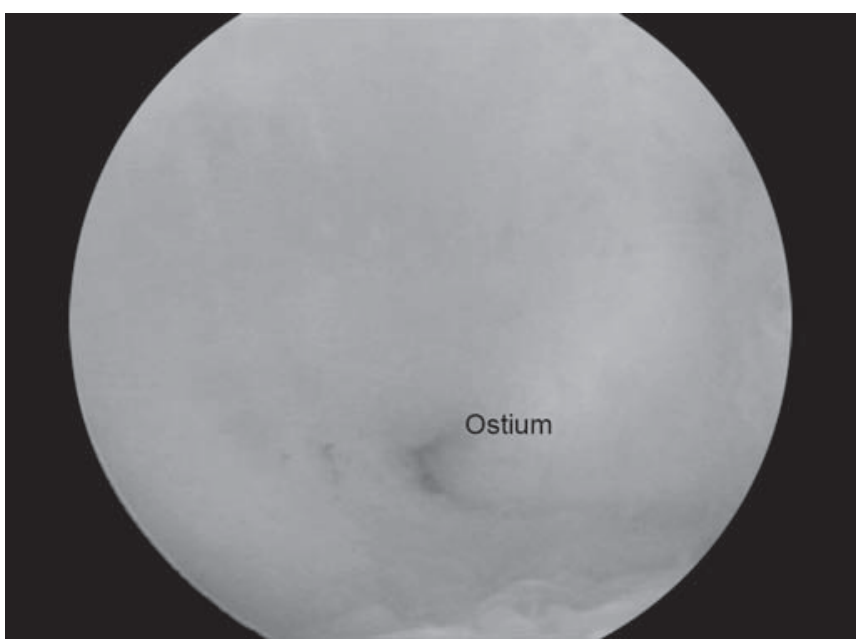

Fig. 6: Right uterine cavity with normal endometrium and right tubal ostium 


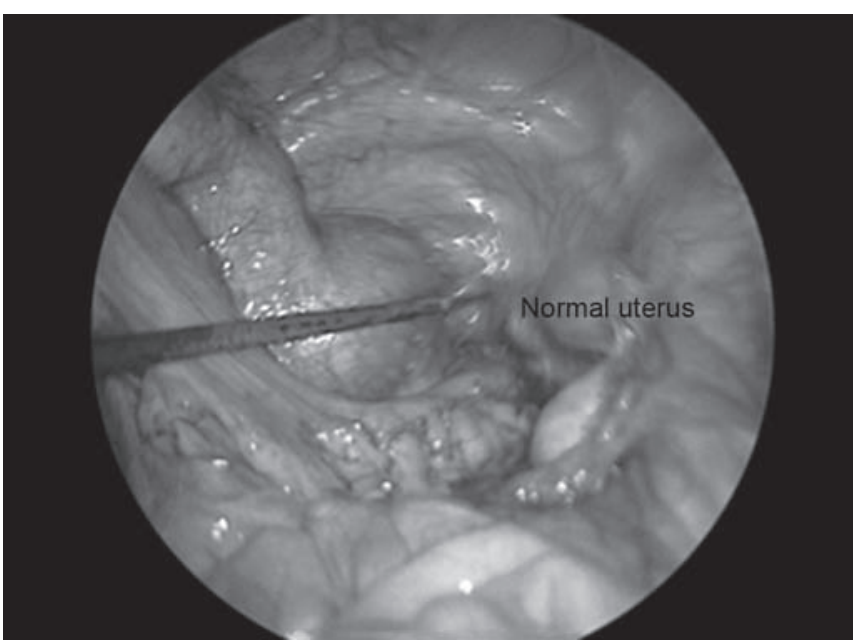

Fig. 7: Laparoscopic view of left hematometra, hematocolpos, and normal right uterus

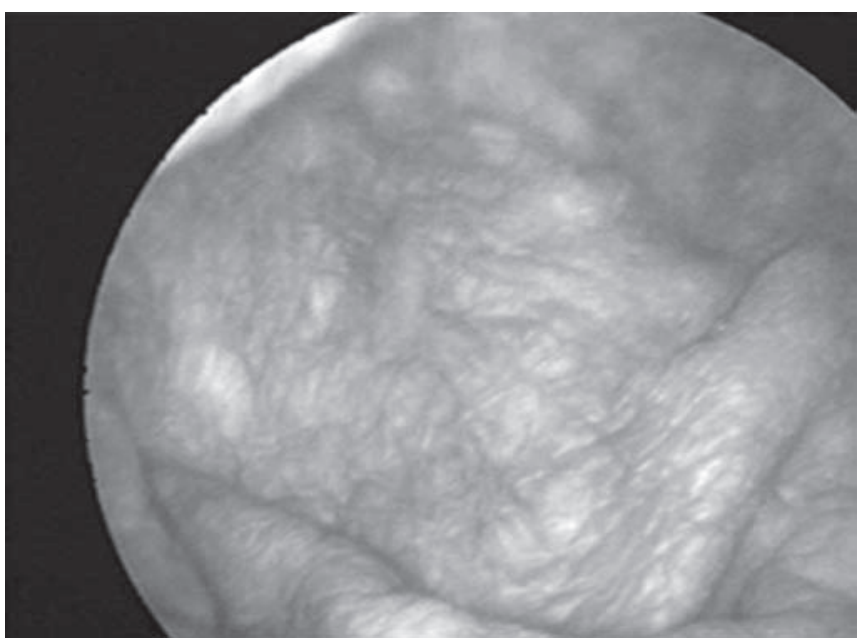

Fig. 9: Well-epithelialized neovagina as seen during vaginoscopy

with normal right horn and fallopian tube, as shown in Figure 7.

Vaginoplasty was planned on the left side. Laparotomy was performed and a small vertical midline incision was made on left horn of uterus following which old chocolate-colored blood was drained out, as shown in Figure 8. Hysteroscopy was done from uterine incision through abdominal route which showed normal endometrium. Vaginoplasty was done by Abbe-McIndoe method. Dilator was inserted into the uterine cavity through abdominal route and felt in new vaginal plane. Incision was given over dilator and a new opening was created, thus connecting cervix to neovagina. Malecots catheter was kept in uterine cavity through the vaginal route to maintain the patency of the tract. Split thickness graft (STG) was taken from medial aspect of thigh; vaginal mould was prepared; and mould inserted in left vagina. Uterine incision was closed with vicryl 1-0. After 8 days, vaginoscopy revealed well-epithelialized left neovagina and hysteroscopy revealed normal cavity with proliferative endometrium on left side, as shown

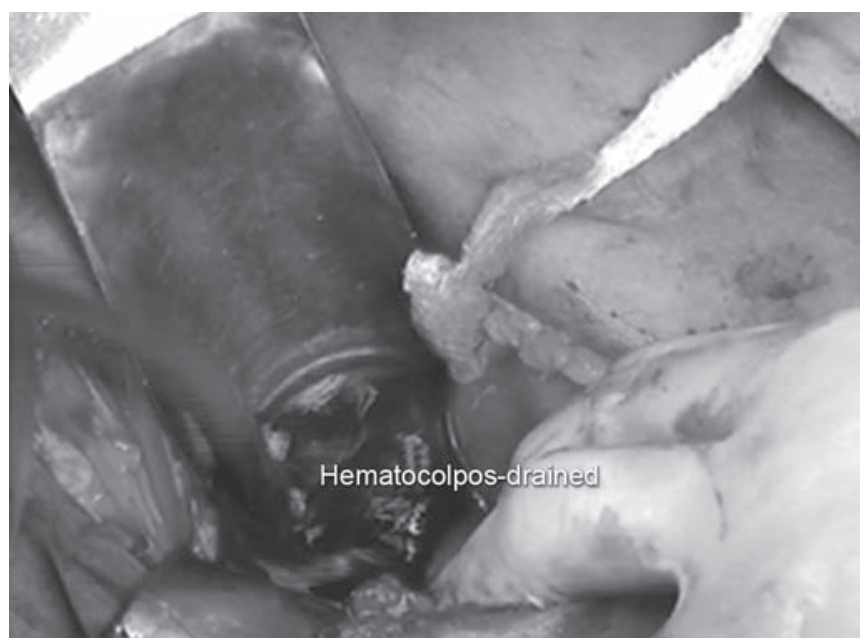

Fig. 8: Hematometra draining through incision over left hematocolpos during laparotomy

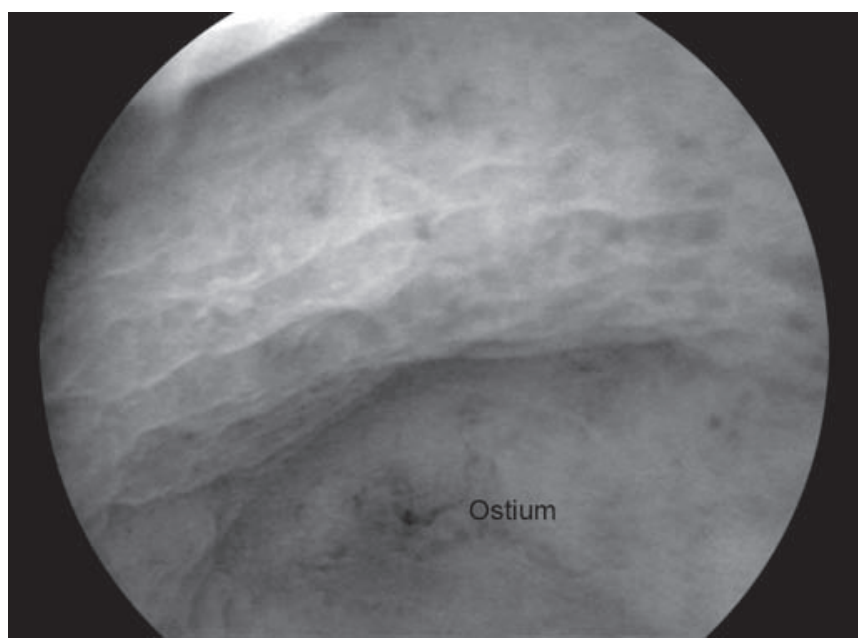

Fig. 10: Healthy left endometrium and ostium visible on hysteroscopy

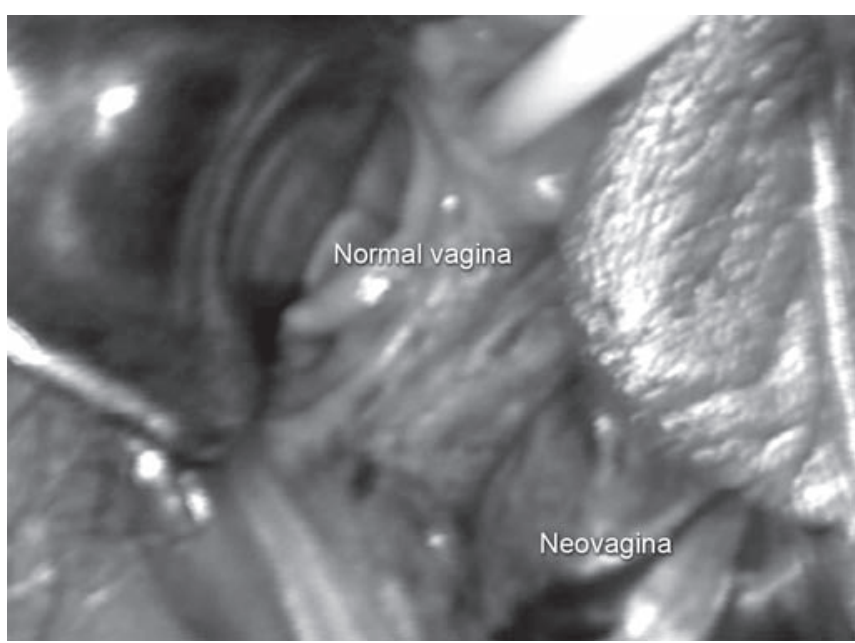

Fig. 11: Normal right vagina with epithelialized neovagina with septum in between

in Figures 9 and 10. Right-sided natural vagina could be easily differentiated from left-sided neovagina by a vertical septum and by different types of epithelium, as shown in Figure 11. Right-sided cervix and endometrial 
cavity were normal. Malecots catheter was kept in situ for 3 months after which vaginal septum resection was done. Vaginoscopy with hysteroscopy showed single vagina with two separate cervices with two uterine cavities with healthy endometrium on either side. On follow-up, patient was asymptomatic with normal regular menstrual cycles.

\section{DISCUSSION}

Stassart et al $^{6}$ observed from 1953 to 1991, a series of 15 such cases and concluded that the most common presentation in these patients is postmenarchal pelvic pain and/or dysmenorrhoea with the presence or absence of palpable pelvic mass and/or vaginal discharge if a communication exists between the two hemivagina. Various diagnostic modalities include transvaginal sonography (TVS), hysterosalpingography (HSG), computed tomography scan, MRI, laparoscopy, and hysteroscopy. Transvaginal sonography can accurately classify mullerian anomalies in 85 to $92 \%$ cases, while MRI has got a diagnostic accuracy in 96 to $100 \%$ of cases. ${ }^{7}$ Orazi et $\mathrm{al}^{8}$ observed 11 adolescent cases and concluded that though ultrasonography may help in the diagnosis of this rare entity, but MRI definitely has an upper hand as it provides detailed uterine morphological details, while also providing correct diagnosis about vaginal channel, i.e., obstructed or nonobstructed. Salim et $\mathrm{al}^{9}$ worked on the diagnostic accuracy of three-dimensional (3D) sonography in congenital uterine anomalies and found that it can diagnose them with acceptable reproducibility. Zurawin et $\mathrm{al}^{10}$ recommended laparoscopy to be considered as gold standard in diagnosing mullerian anomalies.

If an absent or dysplastic kidney is seen in a female fetus on an antenatal scan or a girl postnatally, then it is advisable to screen her for mullerian anomalies also. ${ }^{3}$

This OHVIRA syndrome also known as Herlyn Werner Wunderlich syndrome is rare and consists of a triad of didelphic uterus, obstructed hemivagina, and ipsilateral renal agenesis. ${ }^{11}$ Wilson $^{12}$, first described the association of didelphys uterus with obstructed hemivagina and absent ipsilateral kidney.

Didelphic uterus has maximum association of renal abnormality of about $20 \%$ with it, as compared to any other mullerian anomaly. ${ }^{13}$ Their presentation varies from cyclical abdominal pain, vaginal mass, vaginal discharge to urinary symptoms. The treatment of choice for OHVIRA syndrome involves transverse vaginal septal resection with preservation of normal anatomy with reproductive capabilities. ${ }^{14}$ Modifications in this as well as advancements have always been reported, like hysteroscopic resection of vaginal septum to preserve hymenal integrity. ${ }^{15}$ Purandare et $\mathrm{al}^{16}$ also conserved both the uteri of the patient who presented to them with similar complaints. Various methods of resection of transverse vaginal septum have been proposed with resultant successful term pregnancy. Its management involves correct diagnosis, counseling of the patient and parents, and then undertaking definitive corrective surgery, which would allow her to have healthy sexual life with successful reproductive outcomes. ${ }^{16}$ In this case, we tried to conserve both of her uteri by establishing a communication between the left uterine cavity and left neovagina so as to prevent formation of hematometra. In earlier times, hemihysterectomy was the management for such patients, but it is no longer preferred as pregnancy has been reported in both horns with equal incidence after surgical correction. Altchek and Paciuc ${ }^{17}$ reported pregnancy occurring twice in a previously obstructed didelphys uterus after surgical correction. Therefore, every effort should be made to preserve the obstructed uterus.

\section{CONCLUSION}

Obstructed hemivagina and ipsilateral renal agenesis syndrome is a rare congenital anomaly, which is often missed clinically and is difficult to diagnose. Magnetic resonance imaging is the diagnostic modality of choice. Diagnostic laparoscopy provides additional information regarding pelvic anatomy. A prompt and accurate diagnosis with appropriate surgery aimed at conserving the uterus is required to relieve the symptoms, to prevent complications, and to preserve the sexual and reproductive function.

\section{REFERENCES}

1. Nahum GG. Uterine anomalies. How common are they, and what is their distribution among subtypes? J Reprod Med 1998 Oct;43(10):877-887.

2. Grimbizis GF, Camus M, Tarlatzis BC, Bontis JN, Devroey P. Clinical implications of uterine malformations and hysteroscopic treatment results. Hum Reprod Update 2001 Mar-Apr; 7(2):161-174.

3. Zahran KM, El Aal DEMA, Othman MH, Ahmed ER. Uterus didelphys with imperforate hemivagina and ipsilateral renal agenesis complicated by hematocolpos, hematometra and hematosalpinex. The challenge of intact hymen. Middle East Fertil Soc J 2011;16:291-294.

4. Burgis J. Obstructive Mullerian anomalies: Case report, diagnosis, and management. Am J Obstet Gynecol 2001 Aug;185(2):338-344.

5. Sanfilippo JS, Levine RL. Uterus didelphys with microscopic communication between horns. Am J Obstet Gynecol 1986 Nov;155(5):1055-1056.

6. Stassart JP, Nagel TC, Prem KA, Phipps WR. Uterus didelphys, obstructed hemivagina, and ipsilateral renal agenesis: The University of Minnesota experience. Fertil Steril 1992 Apr;57(4):756-761 
7. Pui MH. Imaging diagnosis of congenital uterine malformation. Comput Med Imaging Graph 2004 Oct;28(7):425-433.

8. Orazi C, Lucchetti MC, Schingo PM, Marchetti P, Ferro F. Herlyn-Werner-Wunderlich syndrome: Uterus didelphys, blind hemivagina and ipsilateral renal agenesis. Sonographic and MR findings in 11 cases. Paediatr Radiol 2007 Jul;37(7):657-665.

9. Salim R, Woelfer B, Backos M, Regan L, Jurkovic D. Reproducibility of three-dimensional (3D) ultrasound diagnosis of congenital uterine anomalies. Ultrasound Obstet Gynaecol 2003 Jun;21(6):578-582.

10. Zurawin RK, Dietrich JE, Heard MJ, Edwards CL. Didelphic uterus and obstructed hemivagina with renal agenesis: Case report and review of the literature. J Pediatr Adolesc Gynecol 2004 Apr;17(2):137-141.

11. Karag'ozov I. Herlyn-Werner-Wunderlich syndrome. Akush Ginekol (Soflia) 1983;22(1):70-76.

12. Wilson JS. A case of double uterus and vagina with unilateral haematocolpos and haematometra. J Obstet Gynaecol Br Emp 1925;32:127-128.
13. Golan A, Langer R, Bukovsky I, Caspi E. Congenital anomalies of the mullerian system. Fertil Steril 1989 May;51(5): 747-755.

14. Dhar H, Razek YA, Hamdi I. Uterus didelphys with obstructed right hemivagina, ipsilateral renal agenesis and right pyocolpos: A case report. Oman Med J 2011 Nov;26(6):447-450.

15. Kim TE, Lee GH, Choi YM, Jee BC, Ku SY, Suh CS, Kim SH, Kim JG, Moon SY. Hysteroscopic resection of the vaginal septum in uterus didelphys with obstructed hemivagina: A case report. J Korean Med Sci 2007 Aug;22(4):766-769.

16. Purandare $C N$, Umrigar $R$, Bandulwalla V, Visarya $N$, Purandare N. Hematometra in uterus didelphys with right hemivagina and right renal agenesis. Case report. J Obstet Gynecol India 2011 Apr;61(2):210-212.

17. Altchek A, Paciuc J. Successful pregnancy following surgery in the obstructed uterus in a uterus didelphys with unilateral distal vaginal agenesis and ipsilateral renal agenesis: Case report and literature review. J Pediatr Adolesc Gynecol 2009 Oct;22(5):e159-e162. 